\title{
KATALIS KARBON YANG DIBUAT DENGAN METODE HUMMERS TERMODIFIKASI UNTUK ASETILASI GLISEROL
}

\author{
Nur Hidayati*, Wahib Khoiruddin, Isnadiah Endang Mastuti, \\ dan Wahyu Devi Satna Pambudi \\ Program Studi Teknik Kimia, Fakultas Teknik, Universitas Muhammadiyah Surakarta \\ Jl. Ahmad Yani Pabelan Kartasura, Tromol Pos 1 Surakarta 57162. \\ *Email: nur.hidayati@ums.ac.id
}

\begin{abstract}
Abstrak
Gliserol adalah produk samping yang dihasilkan dari proses pembuatan biodiesel. Karena peningkatan produksi biodiesel, utilisasi gliserol yang melimpah menjadi asetin berpeluang dilakukan karena manfaat asetin sebagai sumber bahan baku untuk material lainnya yang bernilai lebih. Penelitian ini bertujuan untuk membuat katalis grafena oksida dari multi-walled carbon nanotubes (MWCNT) dengan menggunakan metode hummers termodifikasi. Karakterisasi katalis GO dilakukan dengan menggunakan uji X-Rays Diffraction (XRD) dan Scanning Electron Microscope-Energi Dispersive X-ray (SEM-EDX). Aktivitas katalitik pada asetilasi gliserol menunjukkan konversi yang tinggi mencapai $94 \%$ pada suhu $110^{\circ} \mathrm{C}$ dalam 2 jam reaksi dengan menggunakan katalis $3 \%$ berat.
\end{abstract}

Kata kunci: Asetilasi, Gliserol, Grafena Oksida, Metode Hummers Termodifikasi

\begin{abstract}
Glycerol is a by-product of biodiesel production. Due to the increase in biodiesel production, the utilization of abundant glycerol into acetin has the opportunity to be carried out because of the benefits of acetin as a source of raw material for other materials of higher value. This study aims to prepare graphene oxide catalysts from multi-walled carbon nanotubes (MWCNT) using the modified Hummers method. The characterizations of GO catalyst were assessed using X-Rays Diffraction (XRD) and Scanning Electron Microscope-Energi Dispersive X-ray (SEM-EDX). The catalytic activity of glycerol acetylation showed a high conversion reaching $94 \%$ at $110^{\circ} \mathrm{C}$ in 2 hours of reaction using a $3 \%$ by weight catalyst.
\end{abstract}

\section{PENDAHULUAN}

Cadangan bahan bakar fosil yang semakin menipis dan adanya peningkatan dalam permintaan energi maka harus ada sumber bahan bakar dan bahan kimia alternatif yang berkelanjutan, ramah lingkungan, dan ekonomis (Keogh dkk., 2019). Biodiesel sebagai bahan bakar alternatif terbarukan mengalami peningkatan permintaan selama dekade terakhir ini. Biodiesel diproduksi dari bahan yang mengandung trigliserida seperti minyak dan lemak dengan alkohol. Selain biodiesel, terdapat produk lain yang dihasilkan yaitu gliserol. Peningkatan produksi biodiesel menyebabkan peningkatan pula gliserol. Utilisasi gliserol menjadi penting agar gliserol lebih bernilai ekonomi.

Asetilasi gliserol dengan asam asetat atau asetat anhidrida menghasilkan monoasetin, diasetin, dan triasetin (MAG, DAG, dan TAG) (Liao dkk., 2009). Ester asetat tersebut telah diaplikasikan di industri; MAG dan DAG yang dapat digunakan sebagai biodegradable poliester dan kriogenik, dan TAG yang dapat ditambahkan ke kosmetik sebagai pelembab serta aditif bahan bakar (Rahmat dkk., 2010).

Reaksi asetilasi merupakan reaksi katalitik. Katalis heterogen yang bersifat asam banyak dikembangkan untuk mengatasi permasalahan yang diakibatkan katalis homogen. Katalis heterogen menjadi pilihan karena katalis heterogen yang spesifik dilaporkan memberikan kemudahan pemisahan produk dan katalis serta dapat digunakan berulang karena mudah diregenerasi sehingga lebih ramah lingkungan (Trisunaryanti dkk., 2005). Katalis yang digunakan untuk asetilasi gliserol meliputi: fly ash (Nuraeni dkk., 2019), asam anhidrat (Silva dkk., 2010), lewatit (Setyaningsih dkk., 2017), dan asam nitrat (Nuraeni dkk., 2019), zeolit (Silaban dkk., 2015), zirkonia (Reddy dkk., 2010), tungstophosphoric acid (TPA) dan asam niobic (Balaraju dkk., 2010), amberlyst-35 (Liao dkk., 2010), dan amberlyst-15 (Gonçalves dkk., 2008).

Katalis berbasis karbon aktif berpotensi menjadi katalis untuk asetilasi gliserol karena karbon memiliki struktur amorphous atau 
mikrokristalin dengan luas permukaan yang besar (Fadli dkk., 2019). Salah satu material karbon baru yang berkembang adalah grafena karena susunan atom karbonnya sangat teratur dan hampir sempurna (Taufantri dkk., 2016). Grafena oksida digunakan sebagai katalis supaya mempercepat proses transfer elektron dan proses reduksi iodine/triiodide pada elektrolit. Selain itu Karbon grafena oksida (GO) mempunyai sifat tahan korosi dan memiliki kemampuan elektrokatalis yang baik (Puspitasari, 2017).

Sintesis grafena dapat dilakukan dengan berbagai metode seperti metode micromechanical exfoliation dengan menggunakan scout tape (Novoselov dkk., 2004), penumbuhan epitaxial diatas substrate SiC (Berger dkk., 2004), dan Chemical Vapor Decomposition (CVD) (Li dkk., 2016). Namun metode micromechanical exfoliation tidak efisien untuk dilakukan, sedangkan metode penumbuhan epitaxial dan metode CVD membutuhkan biaya yang sangat mahal. Metode lain yang dapat digunakan adalah metode hummers hummers (Hummers dan Offeman, 1958).

Pada Penelitian ini, katalis grafena oksida dibuat dari multi-walled carbon nanotubes (MWCNT) yang merupakan senyawa anorganik memiliki sifat struktural dan fungsi yang baik seperti rasio serat tinggi serta kekuatan mekanik dan listriknya tinggi (Mittal \& Lin, 2016). Pembuatan grafena oksida dilakukan dengan metode hummers termodifikas (Hummers \& Offeman, 1958) yaitu dengan mereaksikan asam sulfat dan natrium nitrat.

\section{METODOLOGI}

\subsection{Bahan}

Bahan yang digunakan dalam penelitian ini adalah aquades, asam asetat $96 \%$, asam periodat, gliserol, $\mathrm{H}_{2} \mathrm{O}_{2}, \mathrm{HCl} 99 \%$, kalium iodida, kalium dikromat, kloroform, $\mathrm{KMnO}_{4}$, natrium nitrat, dan natrium tiosulfat dari Merck, asam sulfat $98 \%$ dari Mallinckrodt, dan MWCNT dari Jiangsu XFNANO Material China.

\subsection{Cara Kerja}

\subsubsection{Sintesis Grafena Oksida (GO)}

Sebanyak 3 gram serbuk MWCNT dilarutkan dalam $69 \mathrm{ml} \mathrm{H}_{2} \mathrm{SO}_{4} 98 \%$, kemudian 1 gram $\mathrm{NaNO}_{3}$ ditambahkan saat proses pengadukan berlangsung selama 1 jam.
Penambahan 8 gram $\mathrm{KMnO}_{4}$ dilakukan secara bertahap ke dalam campuran setelah pengadukan berlangsung selama 2 jam. Selama 4 jam temperatur dijaga pada suhu $0-20^{\circ} \mathrm{C}$. Campuran diaduk perlahan sampai berubah warna menjadi warna hitam kehijauan. Proses pengadukan dilanjutkan dalam 20 jam pada suhu $35^{\circ} \mathrm{C}$. Setelah 24 jam pengadukan, campuran berubah warna menjadi cokelat muda. Campuran dicuci dengan aquades sebanyak $200 \mathrm{ml}$ dan diaduk selama 1 jam. Untuk menghilangkan sisa $\mathrm{KMnO}_{4}$, campuran ditambahkan $20 \mathrm{ml} \mathrm{H}_{2} \mathrm{O}_{2} \quad 30 \%$. Selanjutnya campuran dicuci dengan $80 \mathrm{ml}$ $\mathrm{HCl}$ dan aquades secara berulang sampai pH netral, kemudian campuran dikeringkan pada suhu $110^{\circ} \mathrm{C}$ selama 12 jam.

\subsubsection{Karakterisasi Katalis}

X-Rays Diffraction (XRD) dilakukan pada sudut $2 \theta=10-90$ dan radiasi $\mathrm{Cu}-\mathrm{K} \alpha$ pada $\lambda$ $=1.54060 \AA$ dan $30 \mathrm{~mA}$ dan $40 \mathrm{KV}$ dengan menggunakan diffractometer X'Pert Pro dari PAnalytical tipe PW 3040/60. Pengamatan morfologi dan elemen katalis dilakukan dengan menggunakan Scanning Electron Microscope-Energi Dispersive X-ray (SEM-EDX) dari JEOL JED-2300 pada 5000x dan $10 \mathrm{kV}$.

\subsubsection{Analisis Konversi Gliserol}

Gliserol dan asam asetat direaksikan dengan perbandingan mol 1:3, dan katalis sebanyak 3\% dari masa asam asetat. Reaksi dilaksanakan pada suhu $110^{\circ} \mathrm{C}$ dan dengan kecepatan pengaduk magnetik $800 \mathrm{rpm}$ dalam labu leher tiga yang dilengkapi dengan pendingin refluks. Sampel campuran reaksi diambil setiap waktu tertentu untuk ditentukan gliserol yang belum bereaksi dengan menggunakan titrasi (Setyaningsih dkk., 2018).

\section{HASIL DAN PEMBAHASAN}

\subsection{Analisis Uji XRD}

Gambar 1 merupakan pola XRD MWCNT dan katalis GO. Pengujian dengan menggunakan XRD ini untuk mengetahui struktur mikro MWCNT dan katalis GO. Dua puncak karakteristik karbon teridentifikasi pada nilai $2 \theta$ sekitar $25^{\circ}$ dan $43^{\circ}$ yang sesuai dengan bidang kristalografi (002) dan (100) secara berturut-turut (Nda-umar dkk., 2021). Pola 
difraksi, nilai $2 \theta$ dari (002) puncak MWCNT bergeser ke kiri dari $25,84^{\circ}$ ke $25,74^{\circ}$ pada GO. Pergeseran difraksi ke kiri menyebabkan peningkatan d-spacing dari $3,445 \AA$ menjadi $3,458 \AA$ yang disebabkan oleh interkalasi dalam tube (intratube) antara ion sulfat dan nitrat dengan silinder grafena koaksial dari MWCNT (Li dkk., 2016). Tingkat keberhasilan pembentukan GO dari pengelupasan MWCNT ditentukan oleh pelebaran dan pergeseran puncak difraksi (002) (Chang dkk., 2014). Penurunan intensitas difraksi pada $2 \theta$ sekitar $25^{\circ}$ pada GO dihubungkan dengan karbon amorf yang terdiri dari lembaran karbon aromatik polisiklik yang diorientasikan secara acak (Nda-umar dkk., 2021). Grafik pola pada GO cenderung lebih rendah dan melebar serta cenderung lebih amorf jika dibandingkan dengan pola MWCNT. Hal ini menunjukkan bahwa jejak bahan awal (MWCNT) dengan luas permukaan katalis yang kecil hadir dalam sampel (Marcano dkk., 2010).

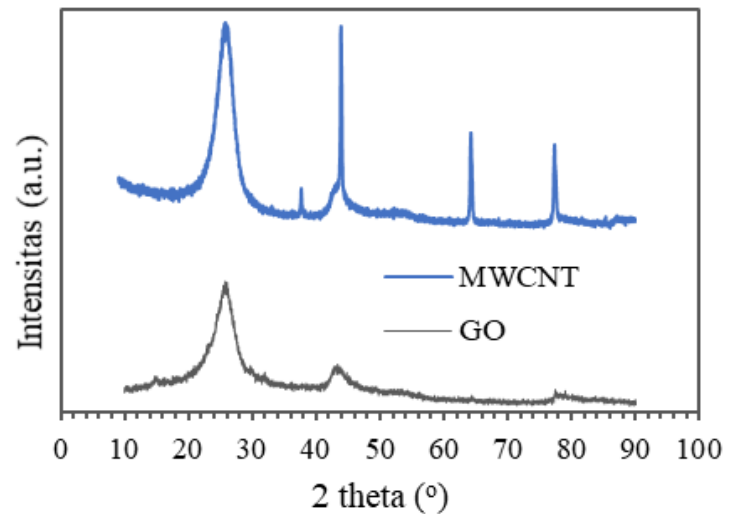

\section{Gambar 1. Difraksi XRD MWCNT dan katalis GO}

\subsection{Analisis Uji SEM-EDX}

Hasil uji SEM-EDX diperoleh berupa gambar struktur morfologi pada perbesaran 5000x dan kandungan unsur dalam katalis (Gambar 2 dan Tabel 1). Perbandingan gambar MWCNT dan GO menunjukkan bahwa beberapa partikel-partikel MWCNT mengalami penggumpalan. Meskipun demikian permukaan GO relatif lebih bersih dari serabut-serabut yang mungkin zat pengotor. Oksidasi karbon tampaknya sukses jika dilihat dari penambahan komponen oksigen pada katalis GO. Terjadi peningkatan persentasi atom ataupun massa oksigen pada GO dari 2,92\% menjadi $28,66 \%$ untuk persentase atom, dan dari 3,84\% menjadi $33,56 \%$ untuk persentase massa. Peningkatan ini bersesuaian dengan susunan atom pada grafena oksida, yang mana atom karbon menunjukkan unsur utama penyusun bahan dan atom oksigen menunjukkan bahan dalam bentuk oksida. Unsur karbon dan oksigen inilah yang menandakan bahwa katalis tersebut merupakan grafena oksida.
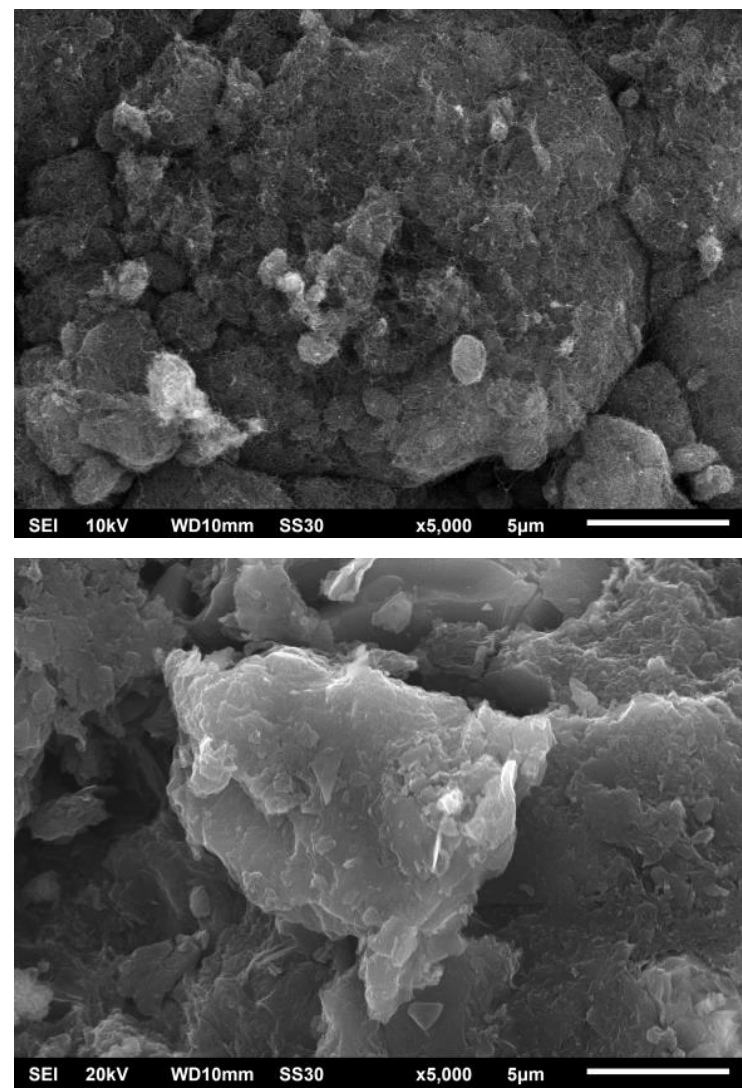

Gambar 2. Hasil uji SEM katalis perbesaran 5000x (a) MWCNT, (b) GO.

Tabel 1. Hasil Uji EDX

\begin{tabular}{|l|r|r|}
\hline Komponen & MWCNT & \multicolumn{1}{|c|}{ GO } \\
\hline \% Atom & \multicolumn{3}{|l|}{} \\
\hline C & 96,90 & 68,59 \\
\hline O & 2,92 & 28,66 \\
\hline Trace & 0,18 & 2,75 \\
\hline \% massa \\
\hline C & 95,76 & 60,30 \\
\hline O & 3,84 & 33,56 \\
\hline Trace & 0,40 & 6,14 \\
\hline
\end{tabular}

\subsection{Analisis Konversi Gliserol}

Kinerja katalis GO pada reaksi asetilasi diuji dengan cara mereaksikan gliserol dengan asam asetat pada suhu $110^{\circ} \mathrm{C}$ dengan penambahan katalis GO sebanyak 3\% dan rasio gliserol-asam asetat 1:3. Gambar 3 merupakan 
konversi gliserol selama reaksi dilangsungkan selama 120 menit.

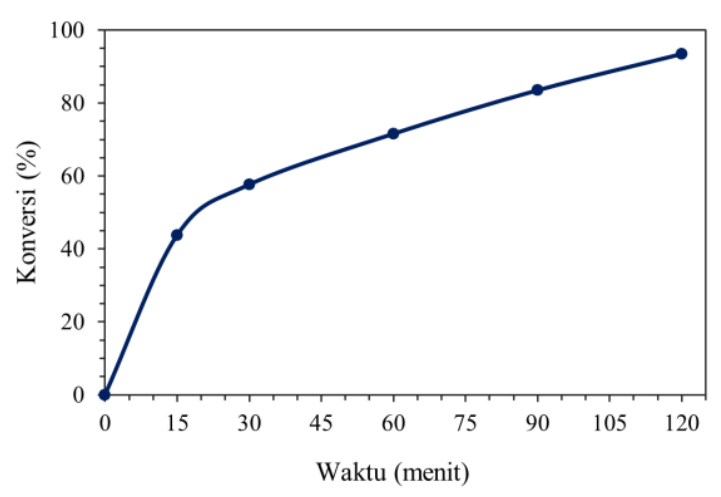

\section{Gambar 3. Grafik hubungan variasi waktu terhadap konversi gliserol}

Terjadi peningkatan konversi gliserol yang signifikan pada 15 menit pertama, sekitar $45 \%$ kemudian diikuti peningkatan yang agak landai sampai 120 menit dan konversi gliserol menjadi asetin mencapai sekitar 94\%. Dilaporkan bahwa konversi gliserol menjadi asetin dengan menggunakan katalis karbon yang diaktivasi dengan asam sulfat mencapai $91 \%$, reaksi dijalankan pada suhu $120^{\circ} \mathrm{C}$ dan rasio gliserolasam asetat 1:8 selama 3 jam (Khayoon \& Hameed, 2011). Peneliti lain melaporkan juga bahwa konversi mencapai $99 \%$ ketika reaksi asetilasi dijalankan pada suhu $120^{\circ} \mathrm{C}$, rasio 1:6 dan jumlah katalis 10\% selama 3 jam (Ndaumar dkk., 2021). Ditinjau dari konversi gliserol dengan membandingkan dengan katalis karbon lainnya, katalis GO ini sangat menjanjikan untuk dikembangkan sebagai katalis asetilasi gliserol untuk menghasilkan asetin.

\section{KESIMPULAN DAN SARAN}

\subsection{Kesimpulan}

Grafena oksida sebagai katalis untuk reaksi asetilasi gliserol telah berhasil dibuat dengan menggunakan metode modifikasi Hummers. MWCNT mengalami perubahan struktur kristal ketika dioksidasi dengan zat pengoksidator kuat, asam sulfat dan natrium nitrat. Konversi gliserol menjadi asetin mencapai sekitar 94\% selama dua jam waktu reaksi, merupakan capaian yang sangat baik dan menjadikan katalis GO layak untuk dikembangkan lebih lanjut.

\subsection{Saran}

Pengujian terhadap katalis GO untuk asetilasi gliserol masih harus dilakukan seperti pengujian karakteristik keberadaan gugus fungsional dengan menggunakan Fourier Transform Infrared, ketahanan terhadap suhu tinggi, tingkat keasaman, dan faktor-faktor yangberpengaruh terhadap reaksi dan optimasi untuk mendapatkan konversi dan selektivitas pembentukan triasetin tertinggi.

\section{DAFTAR PUSTAKA}

Balaraju, M., Nikhitha, P., Jagadeeswaraiah, K., Srilatha, K., Sai Prasad, P. S., \& Lingaiah, N. (2010). Acetylation of glycerol to synthesize bioadditives over niobic acid supported tungstophosphoric acid catalysts. Fuel Processing Technology, 91(2), 249-253.

Berger, C., Song, Z., Li, T., Li, X., Ogbazghi, A. Y., Feng, R., Dai, Z., Marchenkov, A. N., Conrad, E. H., First, P. N., \& Heer, W. A. D. (2004). Ultrathin Epitaxial Graphite: 2D Electron Gas Properties and a Route toward Graphene-based Nanoelectronics. Journal of Physical Chemistry B, 108(52), 19912-19916.

https://doi.org/10.1021/jp040650f

Chang, C., Chang, K., Shen, H., \& Hu, C. (2014). A unique two-step Hummers method for fabricating low-defect graphene oxide nanoribbons through exfoliating multiwalled carbon nanotubes. Journal of the Taiwan Institute of Chemical Engineers, 45(5), 2762-2769.

Fadli, M. Al, Sundari, R., Kasuma, S., \& Ningsih, W. (2019). Katalis Asam Padat Berbasis Karbon Kulit Ubi Kayu Tersulfonasi Untuk Produksi Biodiesel Dari Minyak Sawit, 3(14), 1-8.

Gonçalves, V. L. C., Pinto, B. P., Silva, J. C., \& Mota, C. J. A. (2008). Acetylation of glycerol catalyzed by different solid acids. Catalysis Today, 133-135(1-4), 673-677.

Hummers, W. S., \& Offeman, R. E. (1958). Preparation of Graphitic Oxide, 208, 1339.

Keogh, J., Tiwari, M. S., \& Manyar, H. (2019). Esterification of Glycerol with Acetic Acid Using Nitrogen-Based BrønstedAcidic Ionic Liquids. Industrial \& Engineering Chemistry Research, 58, 17235-17243. research-article.

Khayoon, M. S., \& Hameed, B. H. (2011). Acetylation of glycerol to biofuel 
additives over sulfated activated carbon catalyst. Bioresource Technology, 102(19), 9229-9235.

Li, X., Colombo, L., \& Ruoff, R. S. (2016). Synthesis of Graphene Films on Copper Foils by Chemical Vapor Deposition. Advanced Materials, 28(29), 6247-6252. https://doi.org/10.1002/adma.201504760

Li, Y., Liao, J., Wang, S., \& Chiang, W. (2016). Intercalation-assisted longitudinal unzipping of carbon nanotubes for green and scalable synthesis of graphene nanoribbons. Nature Publishing Group, 6(March), 1-12.

Liao, X., Zhu, Y., Wang, S. G., Chen, H., \& Li, Y. (2010). Theoretical elucidation of acetylating glycerol with acetic acid and acetic anhydride. Applied Catalysis B: Environmental.

Liao, X., Zhu, Y., Wang, S., \& Li, Y. (2009). Producing triacetylglycerol with glycerol by two steps: Esteri fi cation and acetylation. Fuel Processing Technology, 90(7-8), 988-993.

Marcano, D. C., Kosynkin, D. V., Berlin, J. M., Sinitskii, A., Sun, Z., Slesarev, A., Alemany, L. B., Lu, W., \& Tour, J. M. (2010). Improved Synthesis of Graphene Oxide. ACS Nano, 4(8), 4806-4814. https://doi.org/10.1021/nn1006368

Mittal, J., \& Lin, K. L. (2016). Carbon nanotube-based interconnections. Journal of Materials Science, 52(2), 643-662.

Nda-umar, U. I., Irmawati, R., N. Muhamad, E., Azri, N., Ishak, N. S., Yahaya, M., \& Taufiq-Yap, Y. H. (2021). Journal of the Taiwan Institute of Chemical Engineers Organosulfonic acid-functionalized biomass-derived carbon as a catalyst for glycerol acetylation and optimization studies via response surface methodology. Journal of Taiwan Institute of Chemical Engineers, 118, 355-370.

Novoselov, K. S., Geim, A. K., Morozov, S. V., Jiang, D., Zhang, Y., Dubonos, S. V., Grigorieva, I. V., \& Firsov, A. A. (2004). Electric Field in Atomically Thin Carbon Films. Science, 306(5696), 666-669. https://doi.org/10.1126/science.1102896

Nuraeni, N., Yun, Y. F., \& Agustini, M. (2019). Pembuatan Biodiesel dari Minyak Jelantah Menggunakan Adsorben Karbon Aktif dan Pembuatan Triasetin dengan Katalis Asam Nitrat Biodiesel from Waste Cooking Oil using Activate Carbon as
Adsorbent and Synthesis of Triaacetin using Nitric Acid as Catalyst, (1), 17-22.

Puspitasari, W. S. B. D. (2017). Preparasi dan Sintesis Graphene Oxide Dengan Variasi Waktu Pembakaran Kain Perca Menggunakan Metode Penagkapan Asap Dengan Kaca Preparat Berdasarkan Uji Absorbansi dan Gugus- Gugus Fungsional. Jurnal Fisika, 6(5), 439-447.

Rahmat, N., Abdullah, A. Z., \& Mohamed, A. R. (2010). Recent progress on innovative and potential technologies for glycerol transformation into fuel additives: A critical review. Renewable and Sustainable Energy Reviews, 14, 9871000.

https://doi.org/10.1016/j.rser.2009.11.010

Reddy, P. S., Sudarsanam, P., Raju, G., \& Reddy, B. M. (2010). Synthesis of bioadditives: Acetylation of glycerol over zirconia-based solid acid catalysts. Catalysis Communications, 11(15), 12241228.

Setyaningsih, L., Siddiq, F., \& Pramezy, A. (2018). Esterification of glycerol with acetic acid over Lewatit catalyst. MATEC Web of Conferences, 154, 2-5.

Setyaningsih, L. W. N., Rizkiyaningrum, U. M., \& Andi, R. (2017). Pengaruh Konsentrasi Katalis Dan Reusability Katalis Pada Sintesis Triasetin Dengan Katalisator Lewatit. Teknoin, 23(1), 56-62.

Silaban, D. M., Helwani, Z., \& Yenti, S. R. (2015). Esterifikasi Gliserol sebagai Produk Samping Biodiesel Menjadi Triasetin dengan Menggunakan Katalis Zeolit Alam pada Variasi Suhu Reaksi dan Konsentrasi Katalis. JOM FTEKNIK, 2(2), $1-7$.

Silva, L. N., Gonçalves, V. L. C., \& Mota, C. J. A. (2010). Catalytic acetylation of glycerol with acetic anhydride. Catalysis Communications, 11(12), 1036-1039.

Taufantri, Y., Irdhawati, I., \& Asih, I. A. R. A. (2016). Sintesis dan Karakterisasi Grafena dengan Metode Reduksi Grafit Oksida Menggunakan Pereduksi Zn. Jurnal Kimia VALENSI, 2(1), 17-23.

Trisunaryanti, W., Triwahyuni, E., \& Sudiono, S. (2005). Preparasi, Modifikasi Dan Karakterisasi Katalis Ni-Mo/Zeolit Alam Dan Mo-Ni/Zeolit Alam. Teknoin, 10(4), 269-282. 